\title{
EVALUATION OF ETR STABILITY VIA ROD DROP EFFECTS
}

S. R. Gossmann

F. R. Phelps

\section{Aerojet nuclear Company NATIONAL REACTOR TESTING STATION Idaho Falls, Idaho - 8340 I}

\section{MASTER}

DISTRIBUTION OF THS DOCUHENT IS UALIMITED

Date Published -- August 1972

PREPARED FOR THE

U. S. ATOMIC ENERGY COMMISSION

IDAHO OPERATIONS OFFICE UNDER CONTRACT AT(10-1)-1375 


\section{DISCLAIMER}

This report was prepared as an account of work sponsored by an agency of the United States Government. Neither the United States Government nor any agency Thereof, nor any of their employees, makes any warranty, express or implied, or assumes any legal liability or responsibility for the accuracy, completeness, or usefulness of any information, apparatus, product, or process disclosed, or represents that its use would not infringe privately owned rights. Reference herein to any specific commercial product, process, or service by trade name, trademark, manufacturer, or otherwise does not necessarily constitute or imply its endorsement, recommendation, or favoring by the United States Government or any agency thereof. The views and opinions of authors expressed herein do not necessarily state or reflect those of the United States Government or any agency thereof. 


\section{DISCLAIMER}

Portions of this document may be illegible in electronic image products. Images are produced from the best available original document. 
Printed in the United States of America Available from

National Technical Tnformation Service

U. S. Department of Commerce

5285 Port Royal Road

Springfield, Virginia 22151

Price: Printed Copy $\$ 3.00 ;$ Microfiche $\$ 0.95$

\section{LEGAL NOTICE}

This report was prepared as an account of work sponsored by the United States Government. Neither the United States nor the United States Atomic Energy Commission, nor any of their employees, nor any of their contractors, subcontractors, or their employees, makes any warranty, express or implied, or assumes any legal liability or responsibility for the accuracy, complete ness or usefulness of any information, apparatus, product or process disclosed, or represents that its use would not infringe privately owned rights. 
ANCR-1084

S. R. Gossmann

F. R. Phelps

This report was prepared as an account of work sponsored by the United States,Government. Neither the United States nor the United States Atomic Energy Commission, nor any of their employees, nor any of their contractors, subcontractors, or their employees, makes any warranty, express or implied, or assumes any

legal liability or responsibility for the accuracy, completeness or usefulness of any information, apparatus, product or process disclosed, or represents that its use would not infringe privately owned rights.

AEROJET NUCLEAR COMPANY

Date Published -- August 1972

PREPARED FOR THE U. S. ATOMIC ENERGY COMMISSION IDAHO OPERATIONS OFFICE UNDER CONTRACT NO. AT(10-1)-1375 


\section{ABSTRACT}

During the summer and fall of :1971 the ETR intermittently exhibited small periodic power variations. Autonomous oscillation of the reactor was not thought to be the source of these variations because of observed weak power dependence. In order to confirm this opinion, a stability analysis of the reactor was performed using data obtained from a rod drop experiment. This report contains the details of that analysis with the conclusion that the observed power variations could not have been the result of reactor instability or autonomous reactor oscillation. 
CONTENTS

ABSTRACT . . . . . . . . . . . . . . . . . . . . . ii

1. INTRODUCTION. . . . . . . . . . . . . . . . . 1

1.1 Description of Rod Drop Experiment . . . . . . . . . . 1

1.2 Model Definitions and Analysis Procedure . . . . . . . . 2

2. SIMULATION STUDIES. . . . . . . . . . . . . . 4

2.1 Discussion of Experimental Results . . . . . . . . . . 4

2.2. Discussion of Simulation Studies for the "Tril" Region . . 10

2.3 Discussion of Simulation Studies for Prompt Drop Region. . Il

3. STABILITY ANALYSIS. . . . . . . . . . . . . . . 23

4. SUMMARY AND RECOMMENDATIONS . . . . . . . . . . . . 26

5. APPENDIX. . . . . . . . . . . . . . . . 27

6. REFERENCES. . . . . . . . . . . . . . . . 31

FIGURES

1. Experimental power reduction curve, prompt drop region. . . . 5

2. Experimental power reduction curve, "tail" region . . . . . 6

3. Superposition of experimental and simulated power reductions, "tail" region ..................... 8

4. Effect of no delayed feedback on "tail" region of power reduction curve . . . . . . . . . . . . . . . . . 9 9

5. Effect of delayed feedback on "tail" region of power reduction curve . . . . . . . . . . . . . . . . . . . 12

6. Effect of reducing $\tau_{5} 50 \%$................. 13

7. Effect of reducing $K_{D}^{7} 50 \%$.................. 14

8. Effect of increasing $\tau_{3}=\tau_{4} 50 \%$. . . . . . . . . . . . 15

9. Sketch of power reduction curves, prompt drop region. . . . . i6

10. Superposition of simulated and experimental prompt region power reductions. . . . . . . . . . . . . . . . . 19

11. Effect of slower prompt-negative feedback . . . . . . . . . . 19

12. Effect of changes in temperature coefficients . . . . . . . 20

13. Effect of changes in rod worth. . . . . . . . . . . . 20

14. Effect of zero fuel temperature coefficient . . . . . . . . 21

15. Effect of water temperature coefficients. . . . . . . . . 22

16. Open-loop frequency response curves (Nyquist diagrams). . . . 24 TABLES

I. Relative Values of Feedback Model Parameters. . . . . . . . 23 


\section{INTRODUCTION}

During the summer and fall of 1971 the Engineering Test Reactor (ETR) intermittently exhibited small perlodic power variations. Various sources for these fluctuations were postulated and experiments were performed to try to determine the source. One possibility for the source was autonomous oscillation of the reactor itself; although, because of the weak power dependence, this was not considered as a very likely source. In order to confirm this opinion a stability analysis of the reactor was undertaken using data obtained from a rod drop experiment. This report presents the details of this analysis. From the analysis, the possibility that the periodic power variations observed in the reactor at full power could have been the result of reactor instability or autonomous reactor oscillation can be ruled out.

\subsection{Description of Rod Drop Experiment}

Rod drop experiments were performed on December 8, 1971, for the purpose of investigating the dynamic response of the reactor. The measured power reduction curve was to be compared to the calculated response of a reactor model, and the model feedbacks adjusted, as necessary, to attain good agreement between the measured and calculated responses. The experimental procedure required dropping Rod No. 15 from its upper limit at low power $\left(\mathrm{N}_{\mathrm{T}}=0.01 \mathrm{~N}_{\mathrm{F}}\right)$ and again at full power $\left(\mathrm{N}_{\mathrm{F}}\right)$. In both cases the reactor response (power reduction) was measured with a fission chamber operating in the current mode. The chamber was located about three feet from the side of the core and approximately at the vertical midplane. At this position and at full power this chamber produced about $10 \mu \mathrm{A}$ of current. The chamber output signal was recorded on magnetic tape simultaneously with switching signals from the clutch release and rod seat circuits. These latter two signals provided a measure of the time of flight for Rod No. 15. A signal proportional to rod position was not available.

Three rod drops were performed at about $\mathbb{N}_{\mathrm{L}}$ and two were planned at $\mathrm{N}_{\mathrm{F}}$. It was hoped that the $\mathbb{N}_{\text {f }}$ data obtained for Rod No. 15 would be applicable to the $\mathrm{N}_{\mathrm{F}}$ case. The worth and normalized calibration curve of Rod No. 15 obtained ${ }^{F}$ at the two power levels did not agree well enough so that the

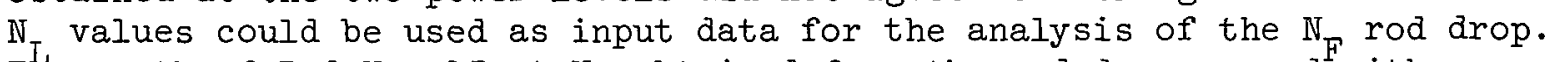
The worth of Rod No. 15 at $\mathrm{N}_{\mathrm{L}}$ obtained from the rod drop agreed with the expected value of about $1.5 \$$. The best value of rod worth from the full power rod drop was about 1.0\$. The difference in worth was qualitatively explained by noting the different positions of other rods relative to Rod No. 15 at the two power levels. This same effect probably also explains the calibration curve shape differences. Reactor operating procedures and other constraints did not allow identical rod positions at the two power levels. The rod drop data obtained at $\mathrm{N}_{\mathrm{L}}$ did serve a useful purpose, however, in confirming the effective time required for the rod reactivity insertion observe 
at $\mathrm{N}_{\mathrm{f}}$ and in providing a measure of the reproducibility of the experiment. The first rod drop from $N_{F}$ did not yield good data for the analysis because of the spurious drop of two other rods following the drop of Rod No. 15. After checking and adjusting the rod release circuits, the second rod drop from $N_{F}$ was successfully executed.

\subsection{Model Definitions and Analysis Procedure}

For purposes of the analysis the full power response was considered to be divided into two parts:

(I) A fast power reduction region of time duration between 200 and 300 msec corresponding to the time during which the rod was in motion.

(2) A much more slowly varying power reduction region starting at about the time the rod. was fully inserted and lasting about 25 seconds.

The first power region will be called the prompt drop region and the latter region will be called the "tail" of the power reduction curve. In this report, the feedback reactivity effects are classified as prompt feedback if the response times of the feedback process are fast enough to affect the prompt drop region of the power reduction. Feedback reactivity effects which are too slow to affect the prompt drop region are called delayed feedback reactivity effects. With these classifications in mind the analysis proceeded along the following lines:

(1) A set of reactor model equations was derived and programmed for solution on an analog computer. The computer simulation initially used included only a prompt-negative feedback reactivity model, the standard zero-power point kinetics model, a dynamic model for rod motion, and a program for simulating the "standard calibration curve" for an ETR rod. This initial model was chosen as a reasonable starting point because it is basically the model used for all reactor transient analyses up to this time. It was necessary to determine if this type of model would produce a response in agreement with the experimental response in both regions of the power reduction curve. The simulation quickly showed that the overall initial model was inadequate in both power reduction regions. This model and subsequent modifications required are discussed in Sections 2.1 and 2.3 of this report.

(2) Using the model described in Item I aboye, the simulation studies showed that the characteristics of the "tail" region were affected mostly by rod worth and by the values assumed for the prompt-negative reactivity feedback coefficient. The assumed rod motion, prompt feedback time constants, and rod calibration curve shape did not affect the tail region so long as the 
simulated power level at the end of the prompt drop matched the experimental value of the power at that time. This result permitted studying the "tail" region dynamics separately from the prompt drop region dynamics.

(3) The prompt drop region dynamics were separated from the "tail" region dynamics by forcing the prompt region model response to match the experimental prompt drop region response. This was accomplished using a technique from adaptive control system theory whereby a system model is continuously and very rapidly modified to make the model rcsponse match the actual system response. In these studies the measured power reduction signal recorded on magnetic tape was used as an input to the computer, compared to the simulated power response during the rod drop, and the difference between these two signals was used to adjust the simulated rod reactivity. The result of this procedure was to establish a set of initial conditions in the simulation at the end of the prompt drop region that matched the experimental data at that time. This procedure permitted experimentation with delayed feedback reactivity models in the simulation until a model that produced good agreement with experimental data in the "tail" region was identified.

(4) After a delayed feedback reactivity model was identified the initial prompt feedback reactivity model was modified as indicated by the simulation studies until good agreement between the simulated response and experimental response in the prompt drop region was obtained.

The feedback reactivity models determined from these studies consist of a prompt-negative feedback model, attributed to the fast thermal response of the fuel plates and the water in the coolant channels, and a delayed feedback model containing both positive and negative components. The delayed-positive feedback is the faster of the two delayed feedback models and can qualitatively, at least in part, be attributed to the response of the experiments. The delayed-negative feedback model was required to produce agreement in the shape of the power reduction curves (simulated vs experimental) in the "tail" region for times exceeding 20 seconds. The details of these various models and further discussions are given in Section 2 of this report. The feedback models obtained in these studies have not been optimized in the sense that the values of the model parameters (gains and time constants) have not been rigorously subjecled to a least square fit, or some other such criteria for goodness of fit, of a model to experimental data. Thus it cannot be claimed that the parameter values are unique. However, parametric studies were performed and it is believed that the final parameter values obtained represent a set of nominal parameter values for the feedback models. Variation of the parameter values of $\pm 50 \%$ produces an observable difference between the simulated and experimental power reduction curves. As would be expected, some parameters are more sensitive than others. The postulated feedback models (at least the prompt-negative and delayed-positive) can be qualitatively related to identifiable physical processes and this lends confidence as to the form of the feedback models as well as to the nominal values of the parameters. 


\section{SIMULATION STUDIES}

\subsection{Discussion of Experimental Results}

As discussed above, the experimental power reduction curve was recorded on magnetic tape. Figures 1 and 2 are plots of this curve showing the prompt drop region and the "tail" region respectively. These two plots were obtained by digitizing the signal, time and amplitude scaling it, and then recording.it using an $X-Y$ recorder. Through this technique it was possible to observe on a larger scale the shape of the prompt drop region without exceeding the X-Y recorder response. On the basis of these curves it would appear that the experimental data do not exhibit any obvious anomalies. The power drops off monotonically as expected, with no indication of any tendency towards oscillation or ringing. Thus, superficially the experimental curve appears to have the shape that would be expected as the result of a fast negative reactivity insertion.

The first point of interest in the experimental results is contained in Figure 1, which shows the prompt drop region. From this curve it appears that negative reactivity has been completely inserted in about $200 \mathrm{msec}$. The power level attained at $200 \mathrm{msec}$ is momentarily held (up to about $350 \mathrm{msec}$ ) as would be predicted from the reactor kinetics equations using the prompt jump approximation. However, if a reasonable rod dynamics model requiring $280 \mathrm{msec}$, as measured, for the rod to fall from its upper limit is combined with the "standard rod. calibration" curve, the effective time required to reduce the power from its initial value to the new value after the rod drop is about $280 \mathrm{msec}$ according to kinetics calculations. Thus the experimental curve indicates a faster rod reactivity insertion than would be predicted on the basis of other experimental data, ie, drop time of the rod and the standard calibration curve. The faster reactivity insertion time indicated by Figure $I$ is not believed to be a consequence of some unknown prompt-positive reactivity feedback process because the power reduction curves measured at low power $\left(\mathbb{N}_{L}\right)$ also showed a reactivity insertion time of $200 \mathrm{msec}$, although the magnitude and shape of the prompt power reduction curves were not the same as measured at high power. This unexpected discrepancy in the prompt drop region has not been explained although several possibilities for the discrepancy can be postulated such as:

(1) The motion of the rod is faster than previously assumed in transient analysis except for some small distance near its lower limit, where the motion must be much slower. The time of flight would still have to be about $280 \mathrm{msec}$ as measured. 


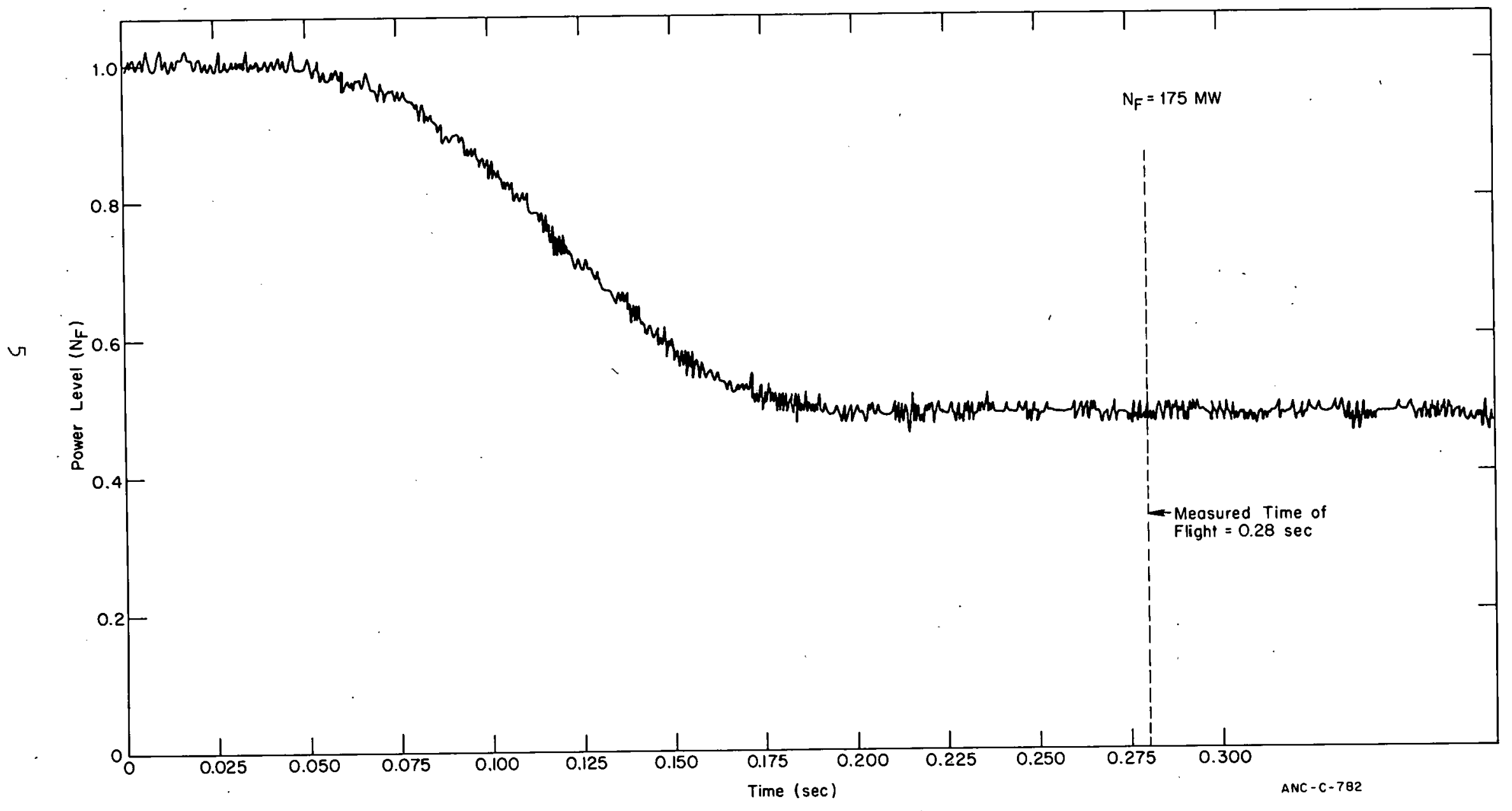

Fig. I Experimental power reduction curve, prompt drop region. 


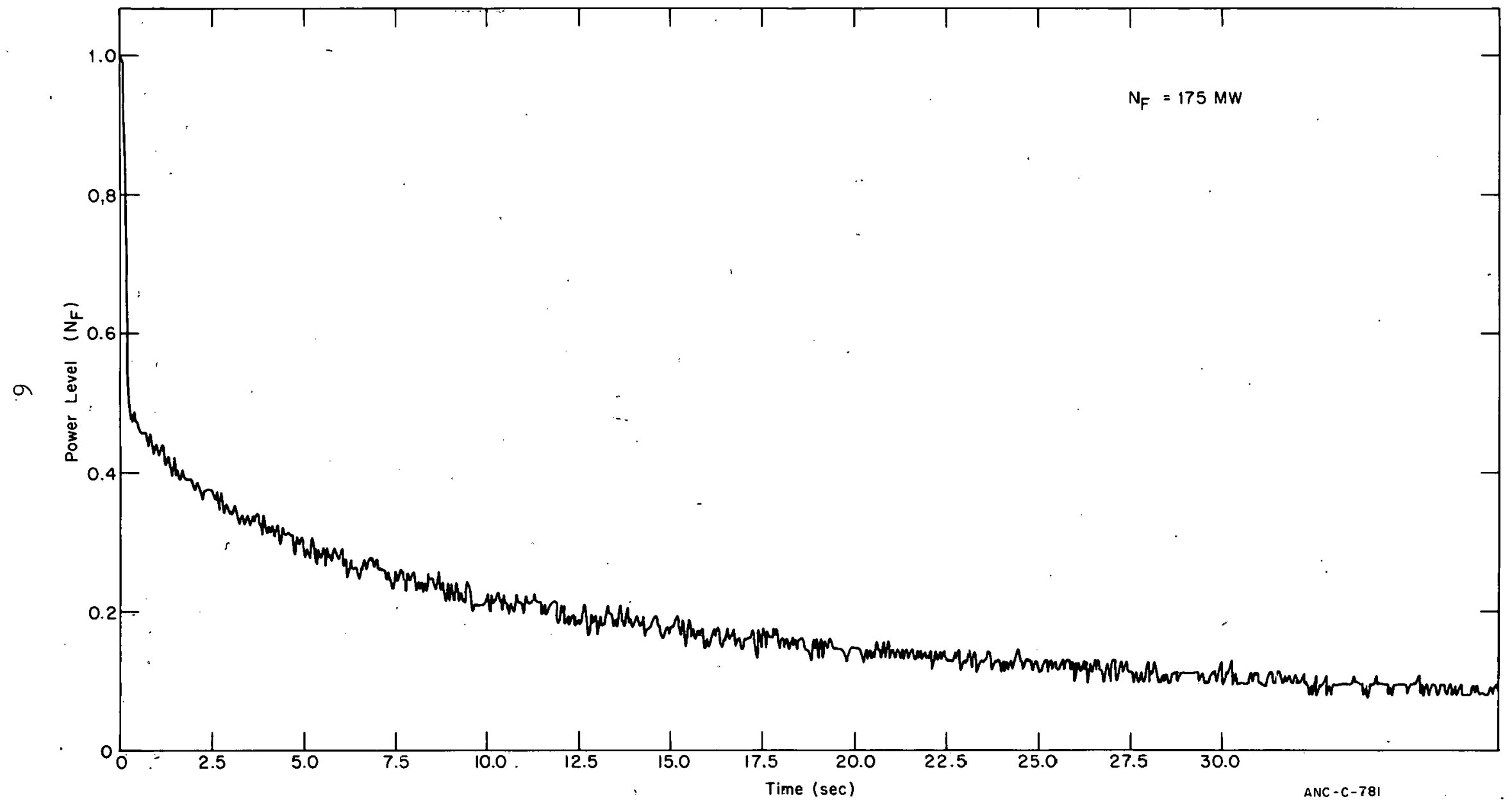

Fig. 2 Experimental power reduction curve, "t๘il" region. 
(2) The shape of the rod calibration curve during a rod drop transient is not the same as the standard calibration curve, particularly near the lower limit of the rod. The rod drop experiment would indicate that this curve has a smaller slope near the lower limit than the standard calibration curve.

(3) The third possibility is the obvious combination of the other two possibilities although it is believed that the first is the most likely. In any event, the effective reactivity insertion time for a rod drop is shown to be smaller than expected and smaller than assumed for accident analyses. If the same effect were shown experimentally to be true for several rods dropped simultaneously as during a scram, it would appear that the accident analyses have been overconservative. Smaller reactivity insertion times would provide greater mitigation of accidents.

It does not appear possible to resolve this discrepancy without a simultaneous measurement of power level and rod position during the rod drop. This problem was arbitrarily resolved in the simulation by forcing the rod reactivity insertion (as a function of time) to produce the correct prompt power reduction given a prompt-negative feedback model based on theoretical and empirical considerations. More will be said about this problem when the prompt-negative feedback model is discussed.

The "tail" of the power reduction curve, Figure 2, also superficially appears to have a shape that would be expected from a rod drop transient. Figure 3 shows the superposition of the experimental curve (direct from the tape recorder) and the power reduction curve obtained from the simulation using the nominal feedback models and parameter values. The ripple in the figure is due to the noisy nature of the experimental signal. This figure shows the good agreement obtained for the "tail" region for times up to 30 seconds. In Figure 4, the "nominal" simulated transient has been reproduced and labeled $N$. The other curve in the figure is the simulated power reduction curve using the nominal prompt-negative feedback model and no delayed feedback. This figure shows that the prompt-negative feedback alone does not produce the correct shape in the "tail" region. For times immediately following the prompt drop region the experimental curve (same as curve $N$ ) decreases more rapidly than is predicted, with only prompt-negative fcedback. For larger times, however, the experimental curve is not decreasing as rapidly as the simulated curve, and at about 25 seconds the curves cross with the simulated power (prompt-negative feedback only) decreasing more rapidly than the experimental power. From this figure it appears that a delayed-positive feedback process, effective for some time following the prompt drop, would produce a power reduction curve more closely resembling the experimental curve; however, the simulation studies showed that a delayed-positive reactivity feedback that continuously increases in magnitude with power level changes does not produce the flattening effect observed in the "tail" for times greater than 25 seconds. The flattening effect could be caused 


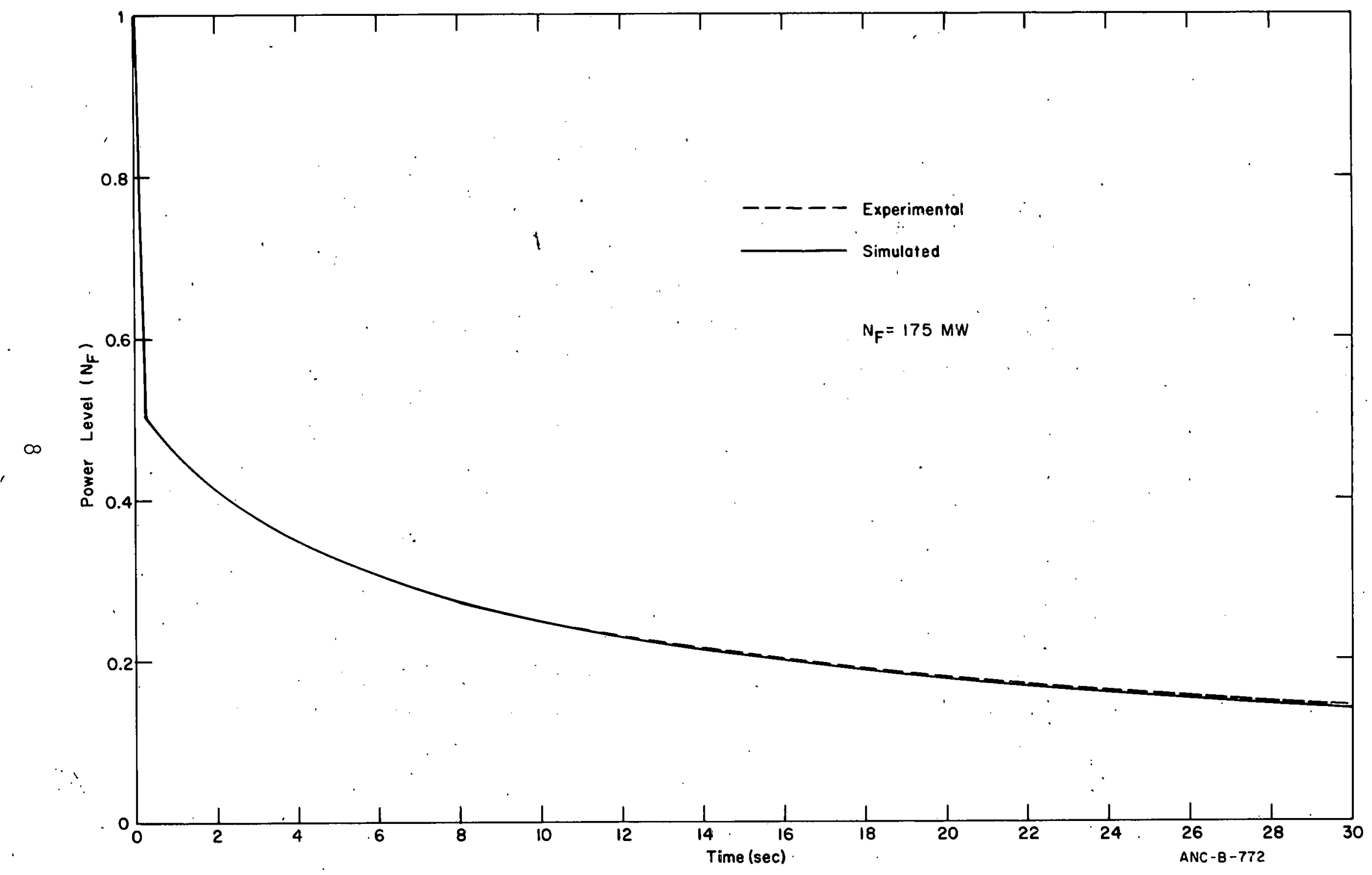

Fig. 3 Superposition of experimental and simulated power reductions, "tail" region. 


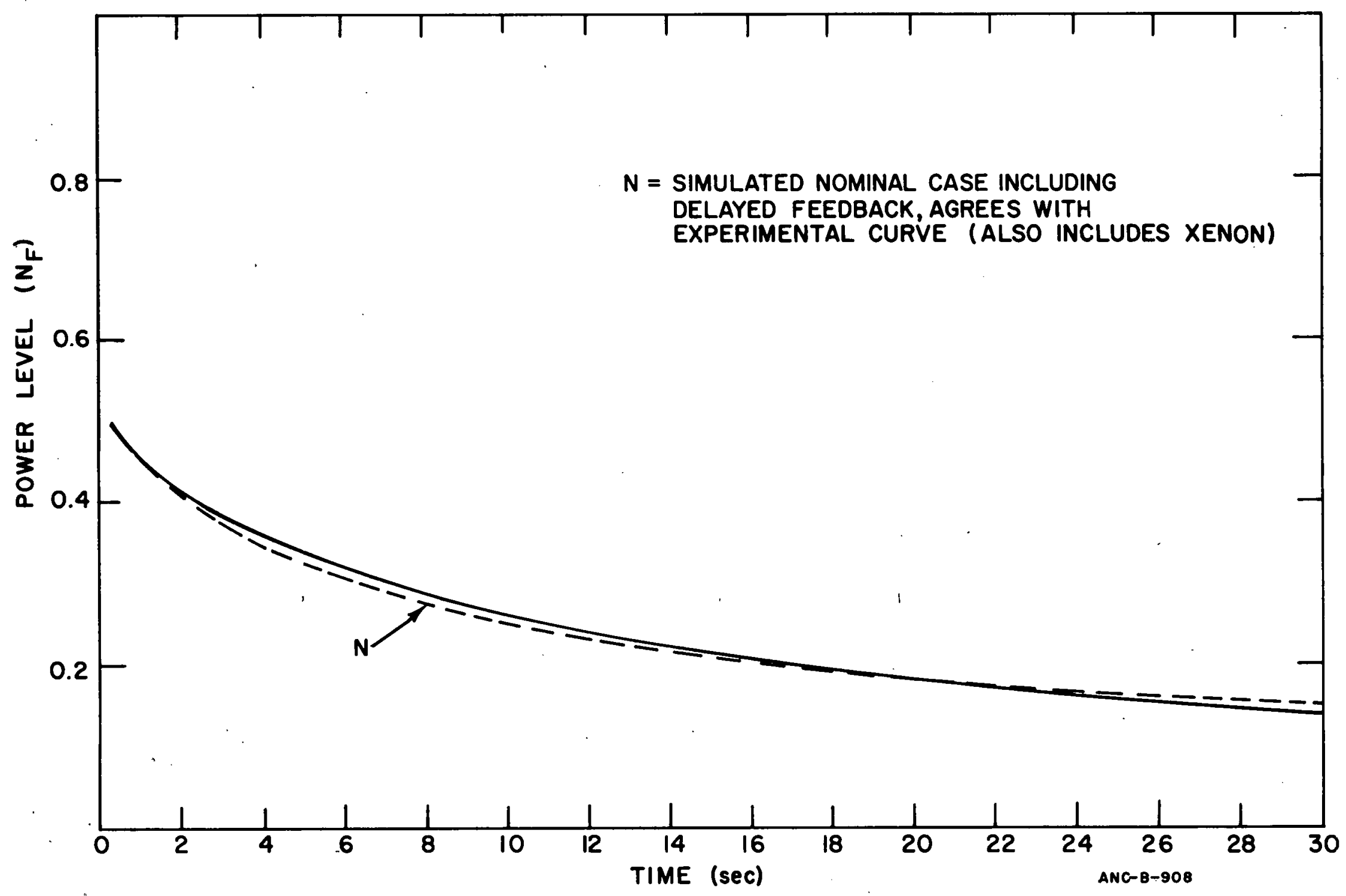

Fig. 4 Effect of no delayed feedback on "tail" region of power reduction curve. 
by a power level bias due to photoneutron sources incident on the . chamber or by the same photoneutron sources acting as an extraneous neutron source also tending to hold up the power level. One other possibility is that the flattening effect could be due to a very slow delayed-negative feedback effect. These various possibilities were investigated in the simulation, resulting in the conclusion that the delayed feedback model must include delayed-positive and delayed negative feedback processes as well as a slow negative reactivity ramp attributed to $135 \mathrm{Xe}$ buildup as a result of the power reduction. These various feedback processes and models are discussed in more detail in the next section.

\subsection{Discussion of Simulation Studies for the "Tail" Region}

In Section 2.1, comparison of the experimental power reduction "tail" region with the simulated power reduction in the same region using only prompt-negative feedback indicated a requirement for some form of delayed-positive feedback. There exist several physical processes which would contribute to an overall delayed-positive feedback such as temperature changes in experiments, temperature changes of the beryllium reflector[1], and temperature changes of water bypassing the fuel elements[1]. Although the latter two processes have positive temperature coefficients of reactivity and are expected to be slow processes, the values of the coefficients and time constants are not. known: The form of the models for these processes could be deduced from physical considerations if necessary; however, the experiments are believed to be the main source of delayed-positive feeduack arid if the model used to represent the experiments includes the action of the experiment control systems, the form of feedback indicated by the experimental power reduction is obtained.

The very simplest form for the delayed-positive feedback reactivity (all processes lumped together) is given by Equation (1).

$$
\rho_{D}^{+}(S)=\frac{K_{D}^{+} S \Delta N(S)}{\left(\tau_{3} S+1\right)\left(\tau_{4} S+1\right)}
$$

where

$$
\begin{aligned}
\rho_{D}^{+}(S)= & \text { Laplace transform, with respect to time, of the reactivity. } \\
& \text { The subscript } D \text { indicates a delayed effect, the }+ \text { superscript } \\
& \text { indicates positive feedback (in phase with the power } \\
& \text { change).[a] } \\
\Delta \mathrm{N}(\mathrm{S})= & \text { Laplace transform of the power change, } \Delta \mathrm{N} .[\mathrm{b}] \\
\tau_{3}, \tau_{4}= & \text { time constants of the process in seconds. } \\
\mathrm{K}_{\mathrm{D}}^{+}= & \text {gain of feedback in units of.. } \$ / \mathrm{MW} / \mathrm{sec} .
\end{aligned}
$$

[a] Reactivity is measured in dollars.

[b] $\mathrm{N}$ is measured in $\mathrm{MW}$. 
This feedback model was studied extensively in the simulation of the rod drop experiment. It should be noted that three parameters are required to quantitatively describe the model, $\mathrm{K}_{\mathrm{D}}^{+}, \tau_{3}$, and $\tau_{4}$. The simulation attempted to determine allowable ranges on these parameters to obtain good agreement with the experimental curve. Initially $\tau_{3}$ and $\tau_{4}$ were assumed to have different values. The extreme range on these values which look promising over part of the "tail" region of the power reduction curve was $\tau_{3}=1 \mathrm{sec}$ and $\tau_{4}=10 \mathrm{sec}$; however, better agreement was obtained with the values of $\tau_{3}$ and $\tau_{4}$ closer together. Finally, for purposes of reducing the number of feedback parameters, $\tau_{3}$ and $\tau_{4}$ were both set at a nominal value of $7.0 \mathrm{sec}$.

In order to obtain better agreement with the experimental response for times of about 25 seconds, delayed-negative feedback was required. This was added to the simulation by modifying the delayed feedback model as in Equation (2).

$\rho_{D}(S)=\frac{K_{D}^{+}\left(\tau_{5} S-I\right) \Delta N(S)}{\tau_{5}\left(\tau_{3} S+I\right)^{2}}$

The simulation studies again varied the parameter $K_{D}^{+}, \tau_{3}$, and $\tau_{5}$ over a wide range of values until a nominal set of values was obtained. These values are:

$$
\begin{aligned}
K_{D}^{+} & =1.14 \times 10^{-2} \$ / \mathrm{MW} / \mathrm{sec} \\
\tau_{3} & =7.0 \mathrm{sec}=\tau_{4} \\
\tau_{5} & =25.0 \mathrm{sec}
\end{aligned}
$$

Figure 5 shows the shape of the simulated power reduction curve in the "tail" region after including the positive and negative delayed feedback effects described above. The curve labeled $N$ is the nominal simulated response (also experimental) which includes a xenon buildup rate of $-0.12 \phi / \mathrm{sec}$. This figure shows good agreement for about 10 seconds following the prompt drop. After 10 seconds the simulated power reduction does not decrease as rapidly as the experimental (curve N); but the previously discussed problem of the crossing of the curves (see Figure 4) has been overcome. At this point the remaining requirement to obtain the agreement shown in Figure 3 was to add the xenon effect. This value of $-0.12 \phi / \mathrm{sec}$ for the xenon buildup appears to be a reasonable value considering the reactor operating history preceding the rod drop experiment[2]. Figures 6,7, and 8 show the effect of $50 \%$ changes in the parameters for this model.

\subsection{Discussion of Simulation Studies for Prompt Drop Region}

Determination of the prompt-negative feedback model required to obtain good agreement between the experimental and simulated power reductions in the prompt drop region was undertaken after the delayedfeedback models were obtained. The prompt-negative feedback model was developed on a semiempirical, semitheoretical basis and reduced to the 


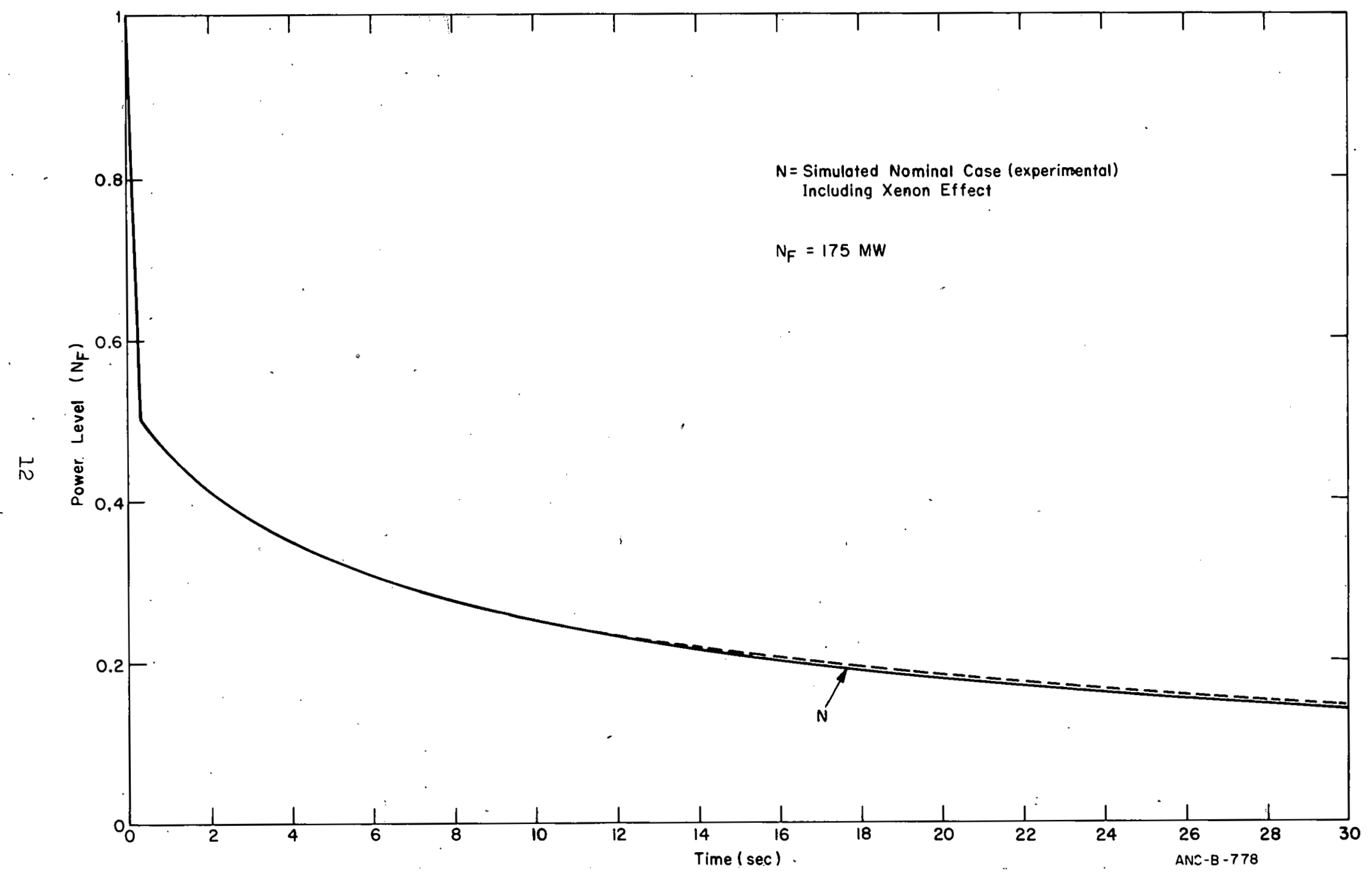

Fig. 5 Effect of delayed feedback on "tail" region of power reduction curve. 


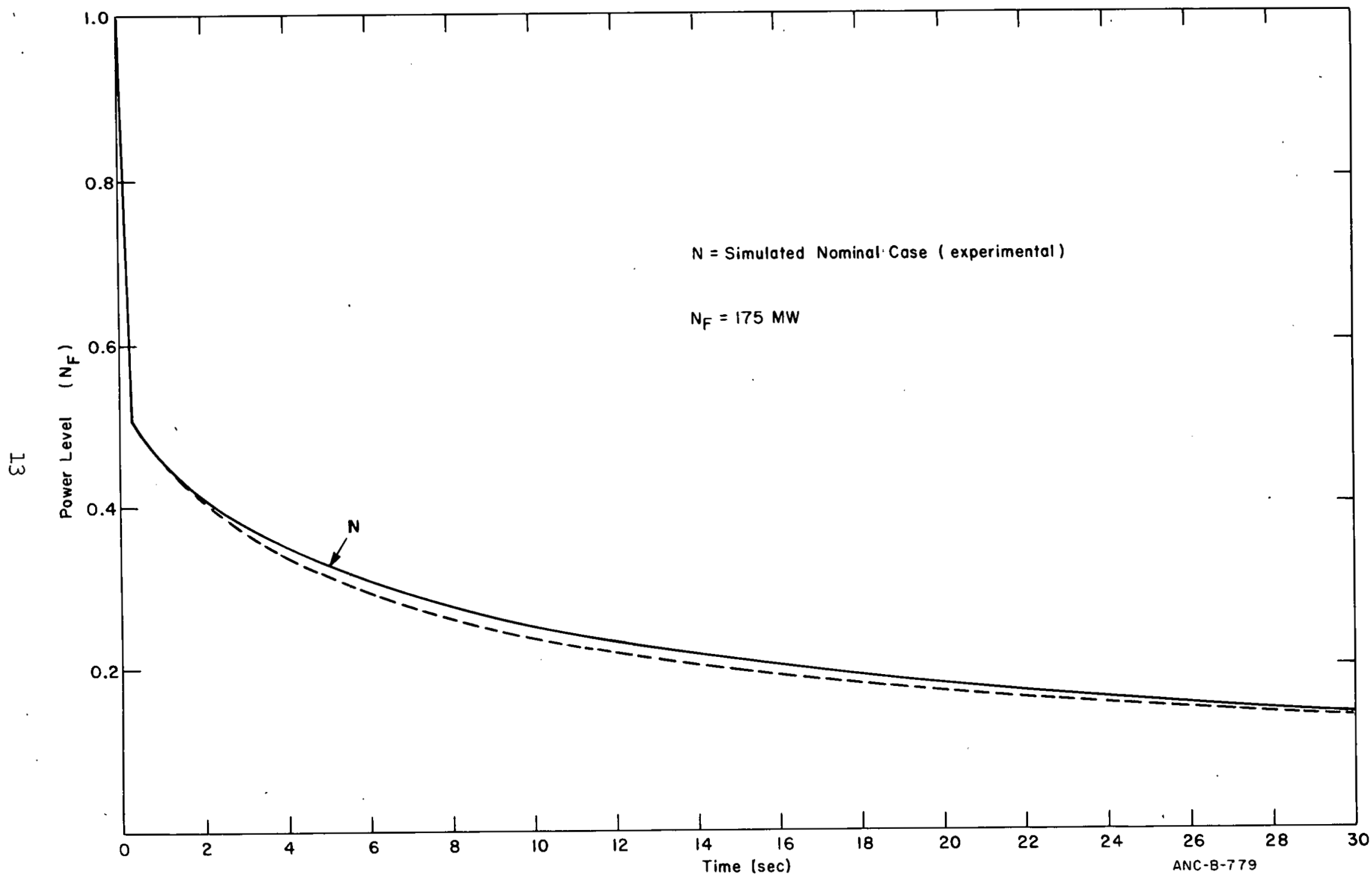

Fig. 6 Effect of reducing $\tau_{5} 50 \%$. 


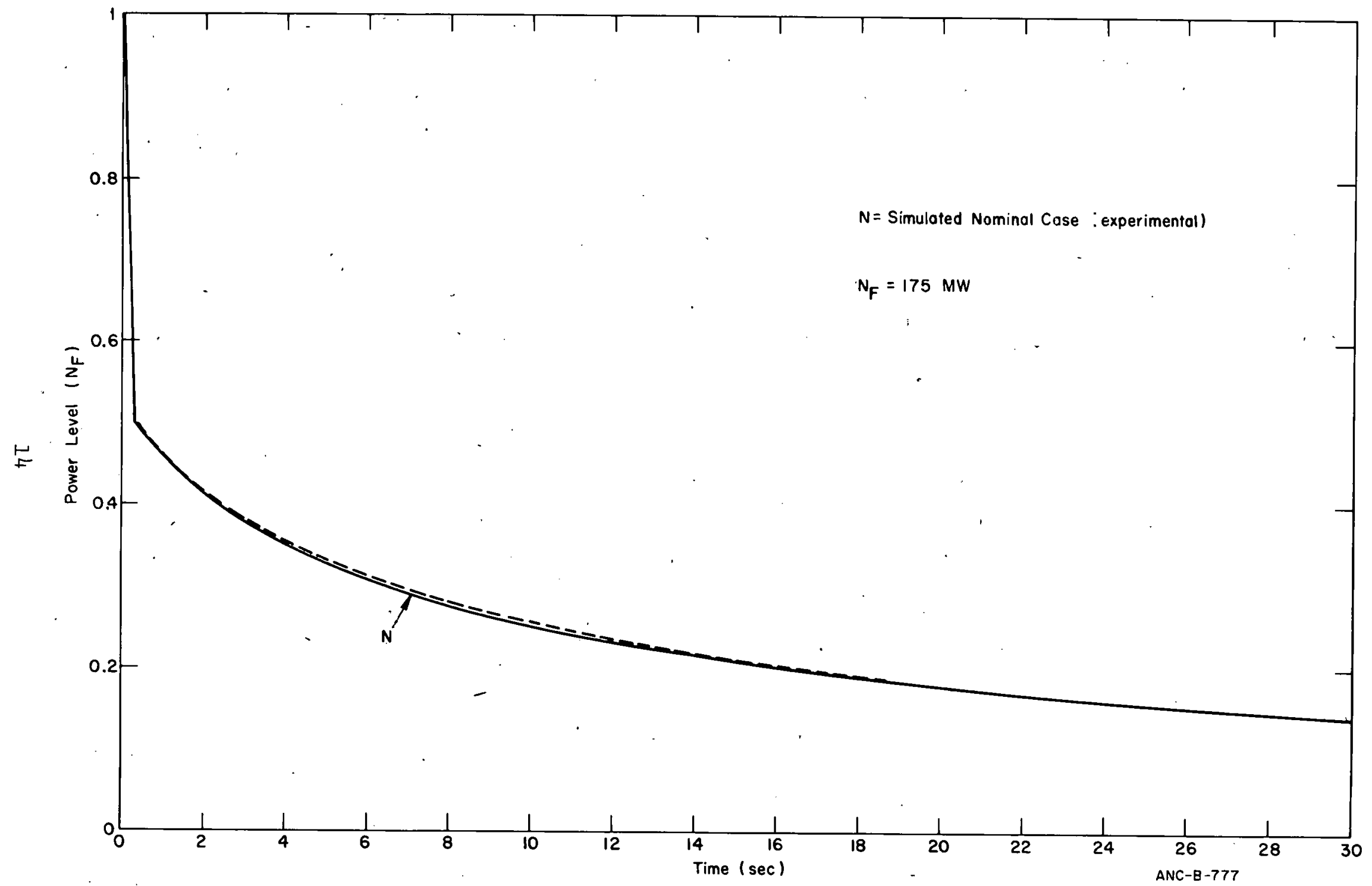

Fig. 7 Effect of reducing $\mathrm{K}_{\mathrm{D}}^{+} 50 \%$. 


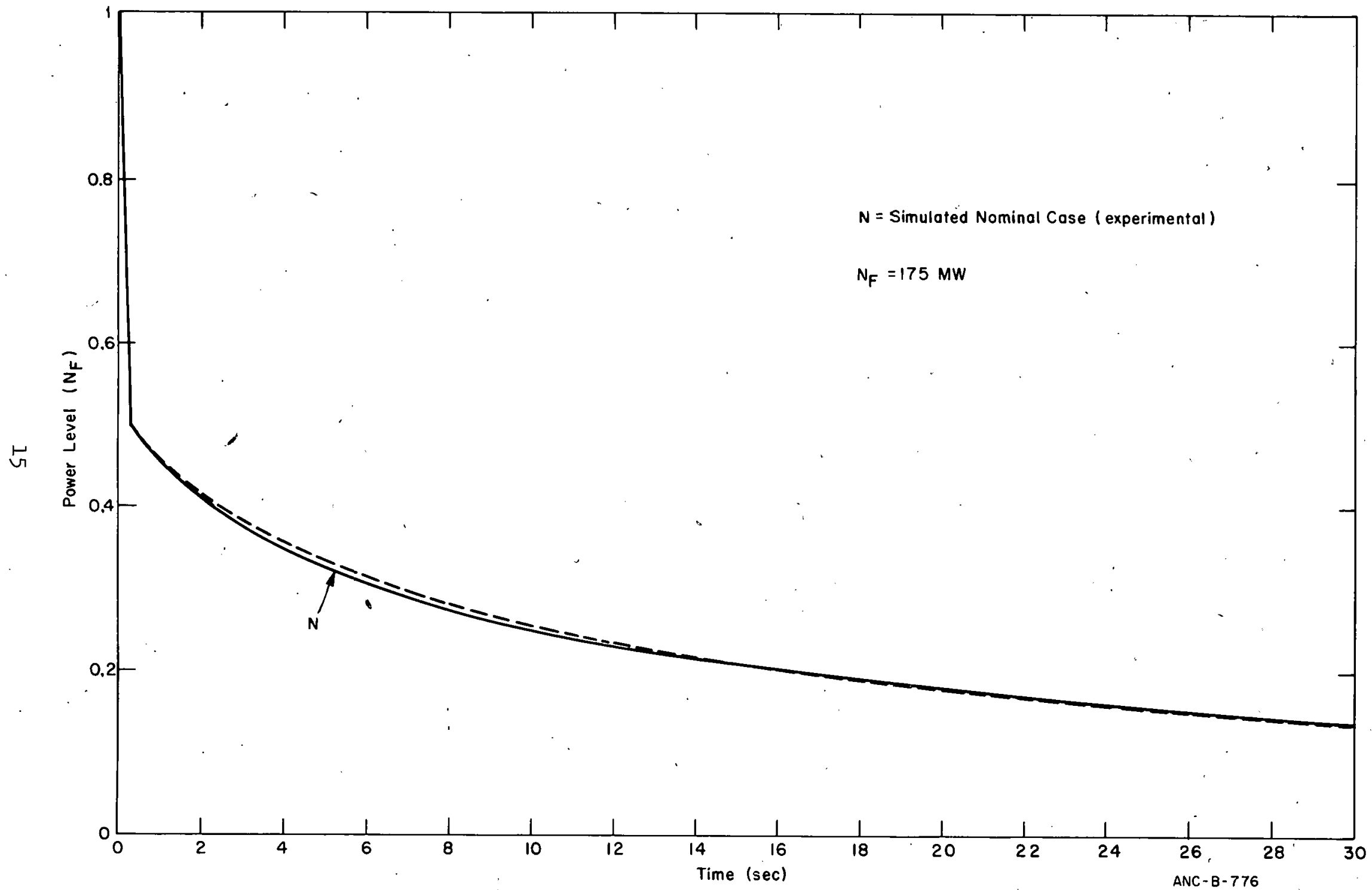

Fig. 8 Effect of increasing $\tau_{3}=\tau_{4} 50 \%$. 
lowest order approximation. The reactor core is assumed to consist of a single fuel region and a single moderator or coolant region; thus, the fuel and moderator (water) temperatures obtained from this model are core average temperatures. The simulation initially assumed that reactivity effects were produced by water temperature changes only and a constant temperature coefficient of reactivity for the water. The simulation studies showed that this form of feedback produced a power undershoot as shown in the sketch of Figure 9, in which the undershoot is exaggerated. This undershoot was not observed in the experimental data, thereby indicating a deficiency in the model. The simulation studies indicated that the undershoot could be eliminated by (a) greatly reducing the temperature coefficient of reactivity, (b) increasing the speed of response of the feedback, or (c) a combination of both. The validity of this particular simplified model was confirmed by the Program for the Analysis of Reactor l'ransients (PARET)[3] digital computer code which assumes basically the same type of feedback, but in which the thermal processes in the core are much more completely described. The results of PARET calculations also exhibited the undershoot obtained from the simpler model. The model was then modified by adding a temperature coefficient of reactivity for fuel plate temperatures in order to speed up the feedback response. An approximate value for this coefficient was obtained from Ref. 4, page 143. By including this effect, the speed of response of the feedback was increased and it was possible to remove the undershoot problem. The nominal feedback model for the prompt-negative feedback is given (in transfer function form) in Equation (3) which is derived in the Appendix.

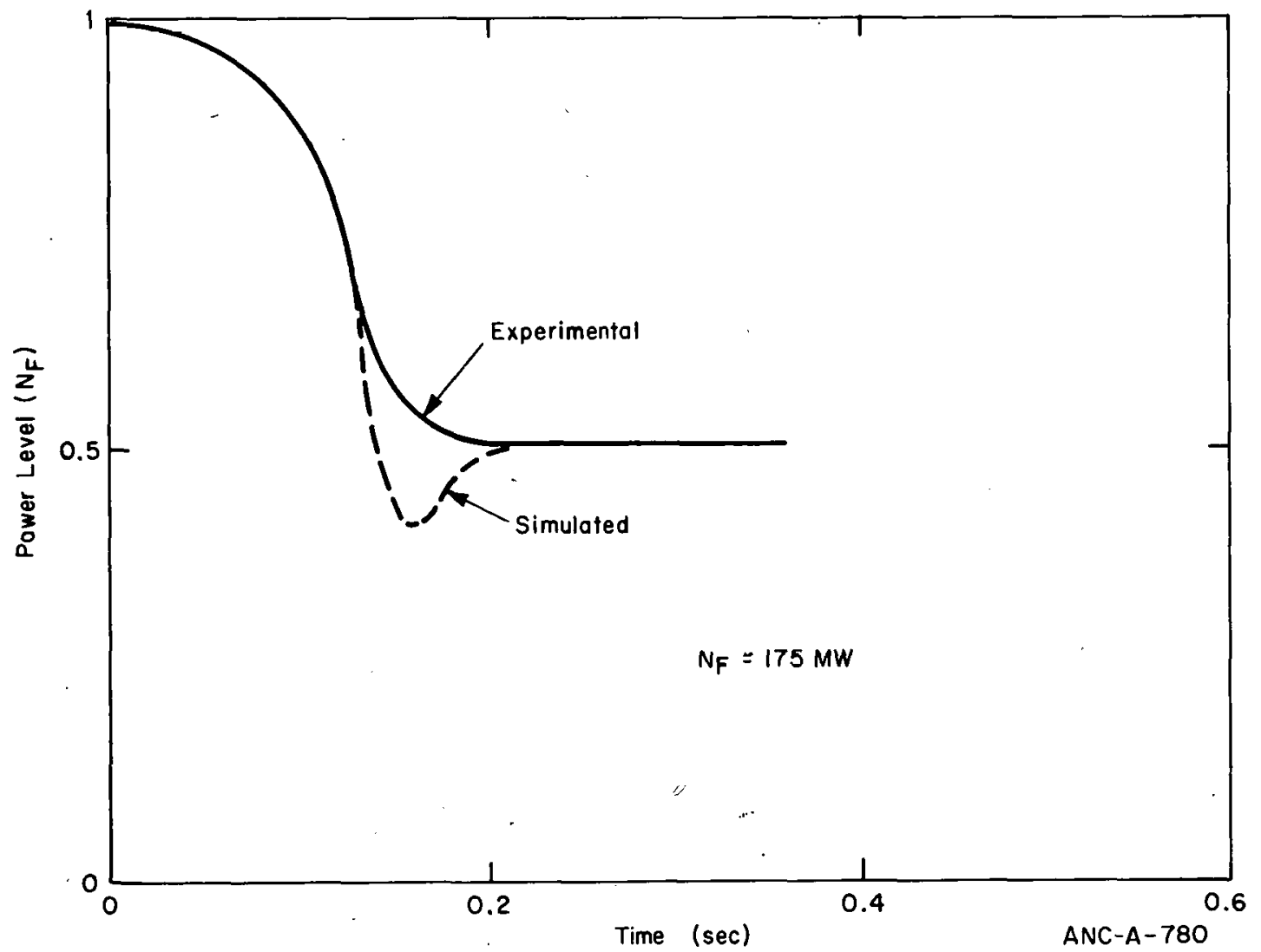

Fig. 9 Sketch of power reduction curves, prompt drop region. 
$\rho_{P}^{-}(S)=\frac{-\bar{c}_{P}^{-}\left(\tau_{0} S+I\right) \Delta N(S)}{\left(\tau_{1} S+l\right)\left(\tau_{2} S+I\right)}$

where

$$
\begin{aligned}
\mathrm{\rho}_{\mathrm{P}}^{-}(\mathrm{S})= & \text { Laplace transform of prompt-negative feedback reactivity } \\
& \text { in dollars } \\
\Delta \mathrm{N}(\mathrm{S})= & \text { Laplace transform of power change in } \mathrm{MW} \\
{ }^{\mathrm{T}} 0, \tau{ },{ }^{\tau_{2}}= & \text { lumped thermal system time constants in seconds } \\
\mathrm{C}_{\mathrm{P}}^{-}= & \text {effective prompt-negative feedback power coefficient in } \$ / \mathrm{MW} .
\end{aligned}
$$

In the simulation $C_{\mathrm{P}}^{-}$was not used as shown in Equation (3). The feedback reactivities were calculated from the temperature changes of the water and fuel using temperature coefficients of reactivity. The temperature coefficient for the water was obtained from Ref. [5] with extrapolation to full power operating conditions. The water temperature coefficient $\mathrm{C}_{\mathrm{T}_{\mathrm{W}}}$ used in the simulation is

$C_{T_{W}}=A+B \Delta T$

where

$$
\begin{aligned}
\mathrm{C}_{\mathrm{T}_{\mathrm{W}}}= & \text { water temperature coefficient in } \$ /{ }^{\circ} \mathrm{F} \\
\mathrm{A}= & 5.72 \times 10^{-3} \$ /{ }^{\circ} \mathrm{F} \\
\mathrm{B}= & 6.65 \times 10^{-5} \$ /\left({ }^{\circ} \mathrm{F}\right)^{2} \\
\Delta \mathrm{T}= & \text { change in average water temperature from initial full power } \\
& \text { value in }{ }_{\mathrm{F} .}
\end{aligned}
$$

The fuel temperature coefficient $C_{T_{f}}$ was assumed to have a nominal value of $0.1 \mathrm{~A}$.

The nominal values of the time constants $\tau_{1}$ and $\tau_{2}$ were calculated using the thermal properties of the system. The time constant $\tau_{0}$ is a complicated function of the thermal properties, the temperature coefficients $A$ and $C_{T_{f}}$, and the prompt energy partition which was taken as $93 \%$ in the fuel and $4 \%$ in the water. The nominal values for these parameters used in the simulation are:

$$
\begin{aligned}
\tau_{0} & =0.01 \mathrm{sec} \\
\tau_{1} & =0.02 \mathrm{sec} \\
\tau_{2} & =0.067 \mathrm{sec} \\
C_{T_{f}} & =5.72 \times 10^{-4} \$ /{ }^{\circ} \mathrm{F}
\end{aligned}
$$

$A$ and $B$ are given above. 
The degree of agreement obtained between the simulation using the nominal prompt-negative feedback model described and the experimental power reduction in the prompt drop region is shown in Figure 10 where the two curves are superimposed for comparison. The worth of the rod to produce this agreement is $0.995 \$$.

In Figure 11 is shown the effect of increasing the prompt-negative feedback time constants $\tau_{0}, \tau_{1}$, and $\tau_{2}$ simultaneously by $50 \%$. As in previous figures, the nominal (or experimental) curye is labeled $N$. This figure indicates that at the nominal values, the feedback is fast enough that a 50\% increase in time constants has very little effect although it can bc seen that the undershoot problem could become pronounced if the increase were much larger.

Figure 12 shows the effect of $\pm 50 \%$ changes in all three components (simultaneously) of the temperature coefficients $\mathrm{A}, \mathrm{B}$, and $\mathrm{C}_{\mathrm{T}_{\mathrm{f}}}$ while holding the rod worth fixed at $0.995 \$$. As previously discussed this figure shows that increasing the temperature coefficients produces the undershoot effect.

Figure 13 simply shows the effect of $\pm 5 \%$ changes in rod worth with nominal prompt-negative feedback.

Figure 14 shows the effect on the "tail" region of the power reduction curve if the fuel temperature coefficient is set at zero. As would be expected, under this condition there is less negative feedback throughout the transient and thus the simulated power reduclion curve is always lower. In order to match the prompt drop in power, rod worth would have to be reduced or the water temperature coefficient would have to be increased.

Figure 15 shows the effect of $50 \%$ changes in water temperature coefficient ( $A$ and $B$ changed simultaneously). 


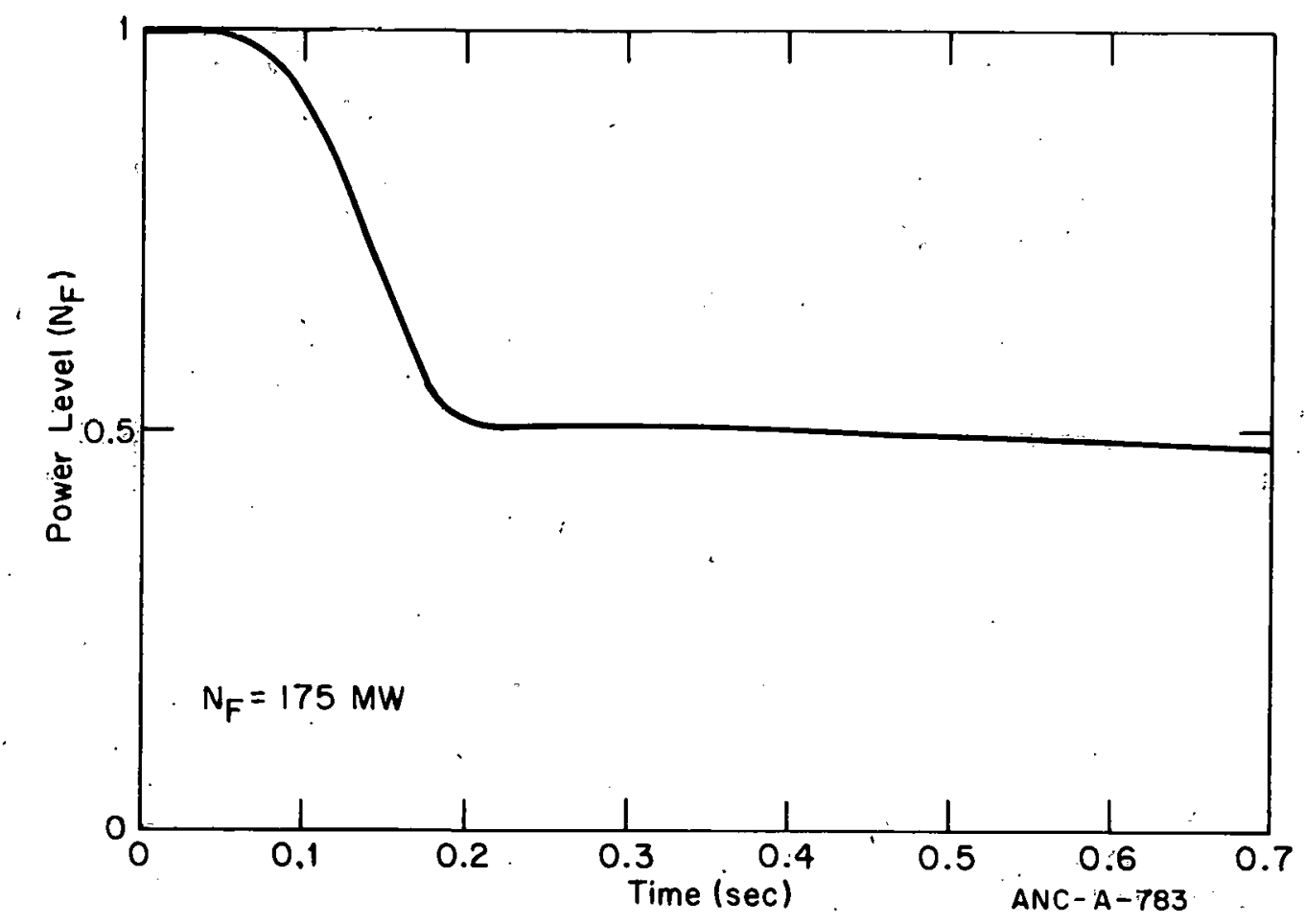

Fig. 10. Superposition of simulated and experimental prompt region power reductions

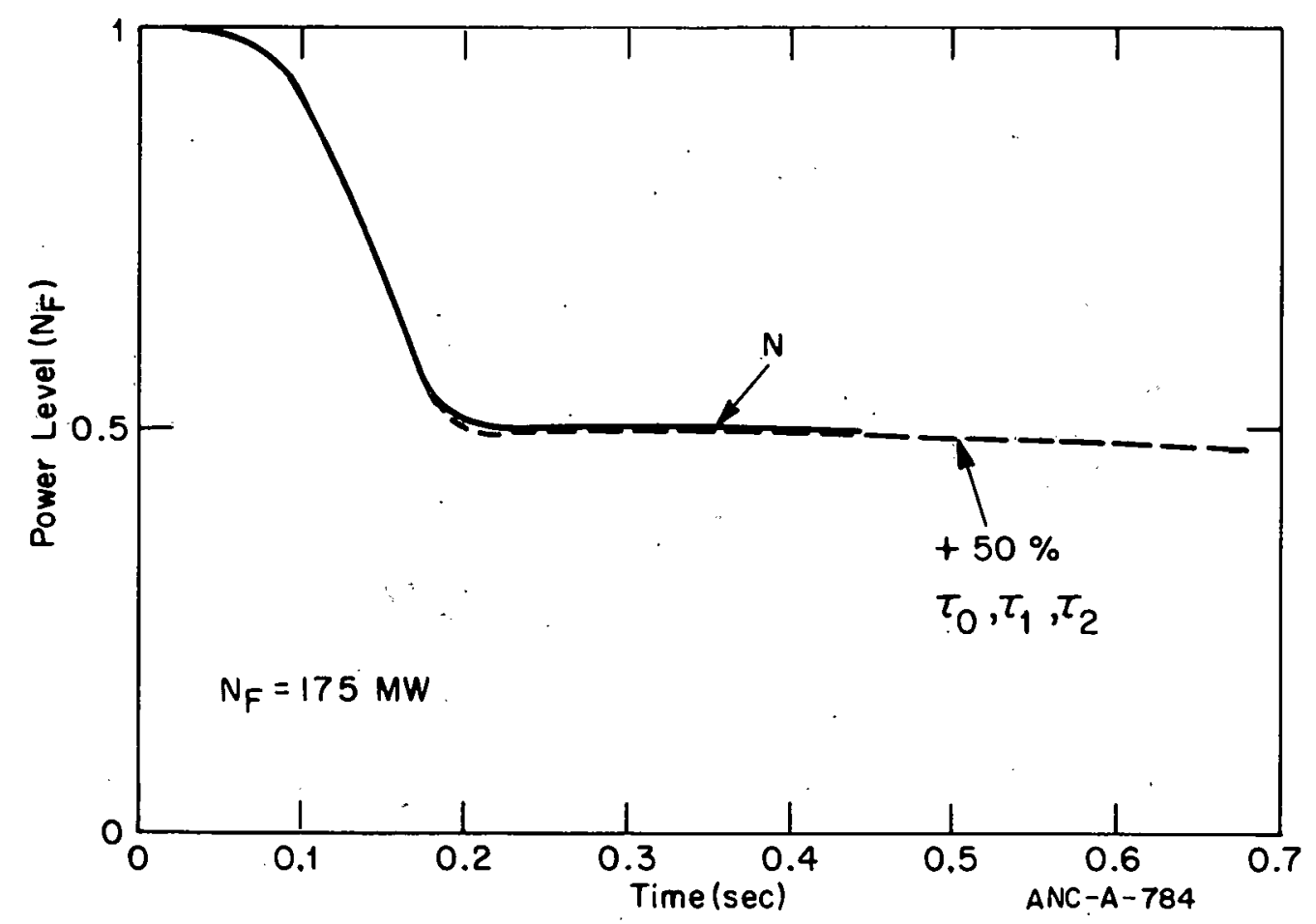

Fig. 11 Effect of slower prompt-negative feedback. 


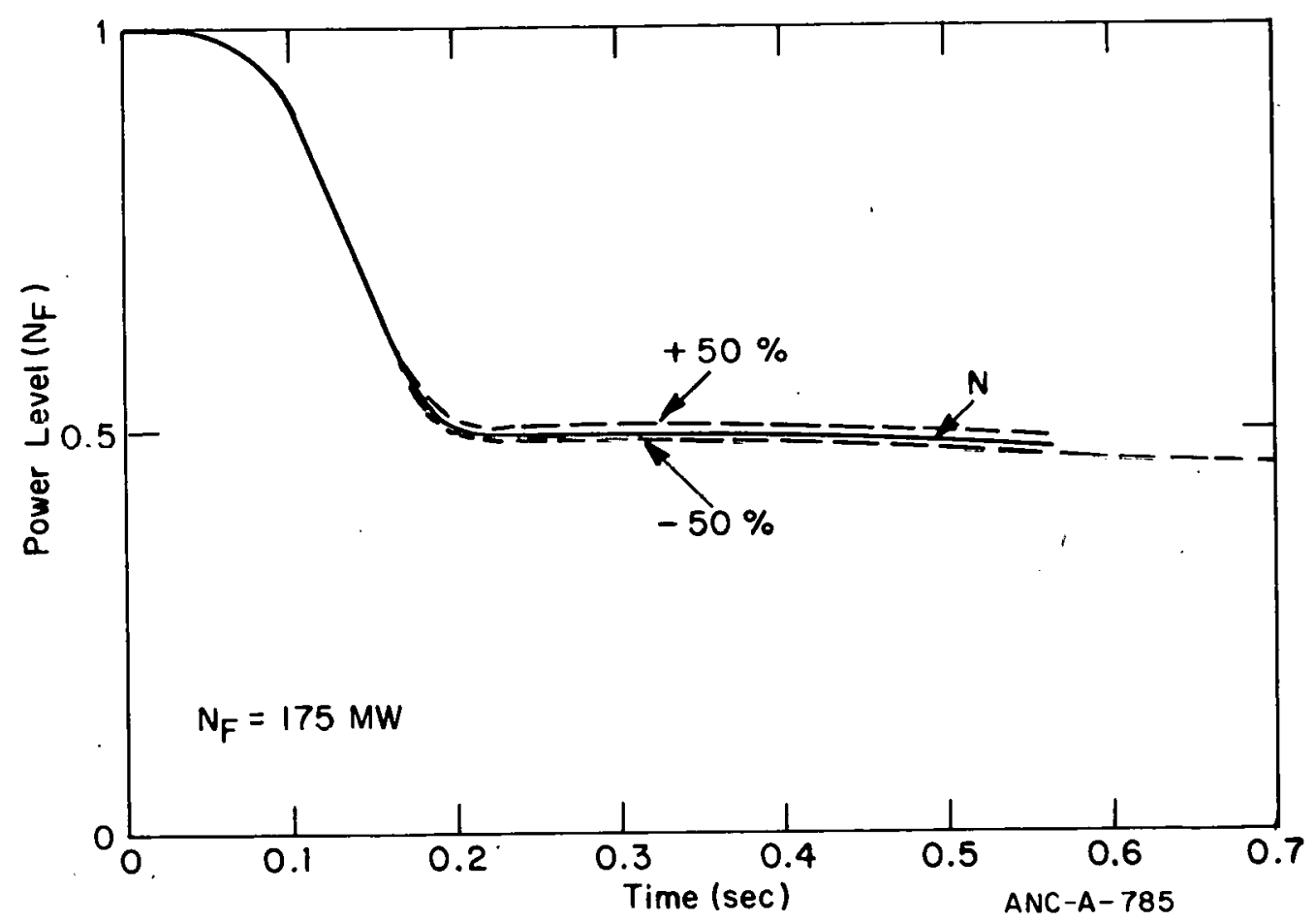

Fig. 12 Effect of changes in temperature coefficients.

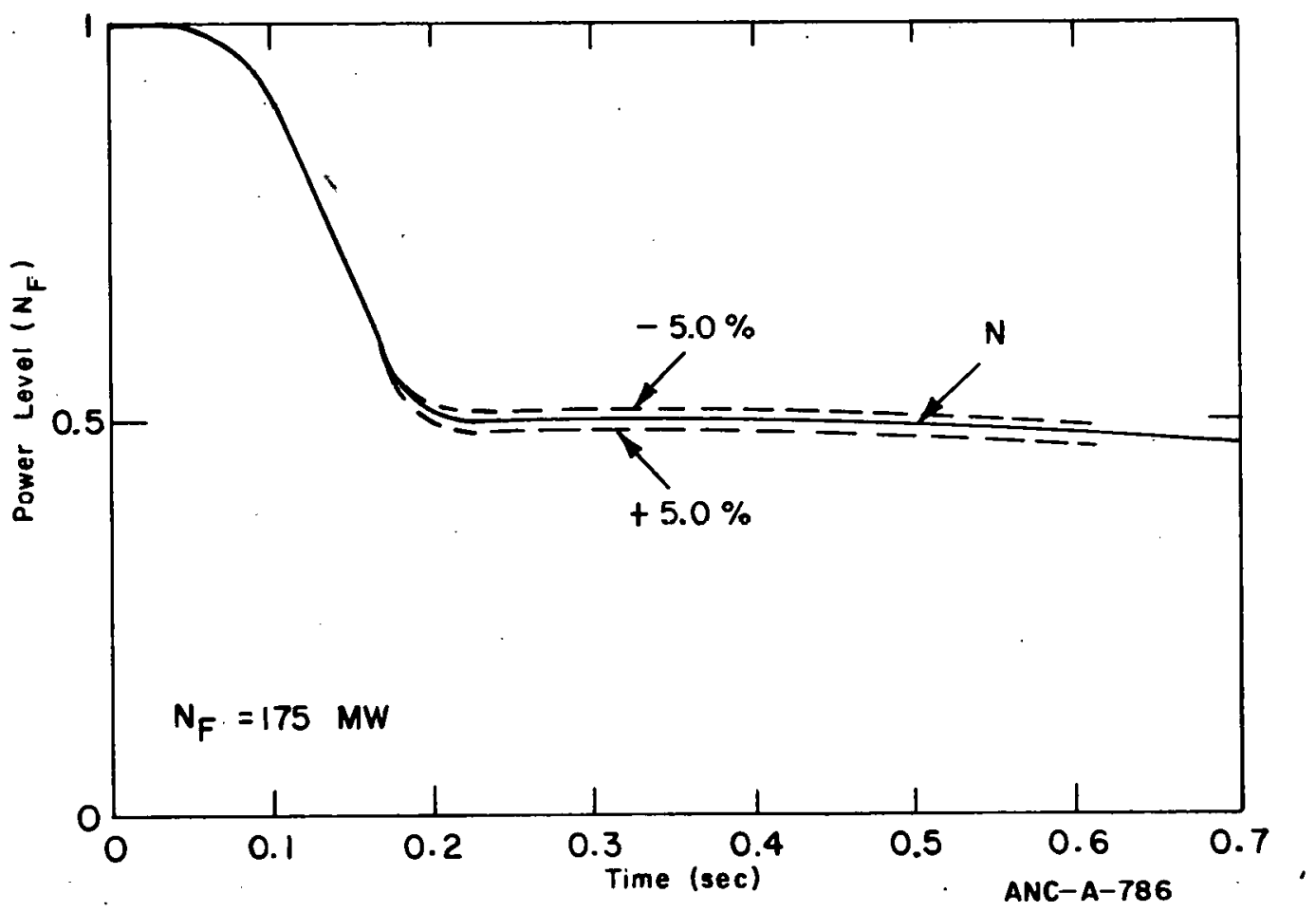

Fig. 13 Effect of changes in rod worth. 


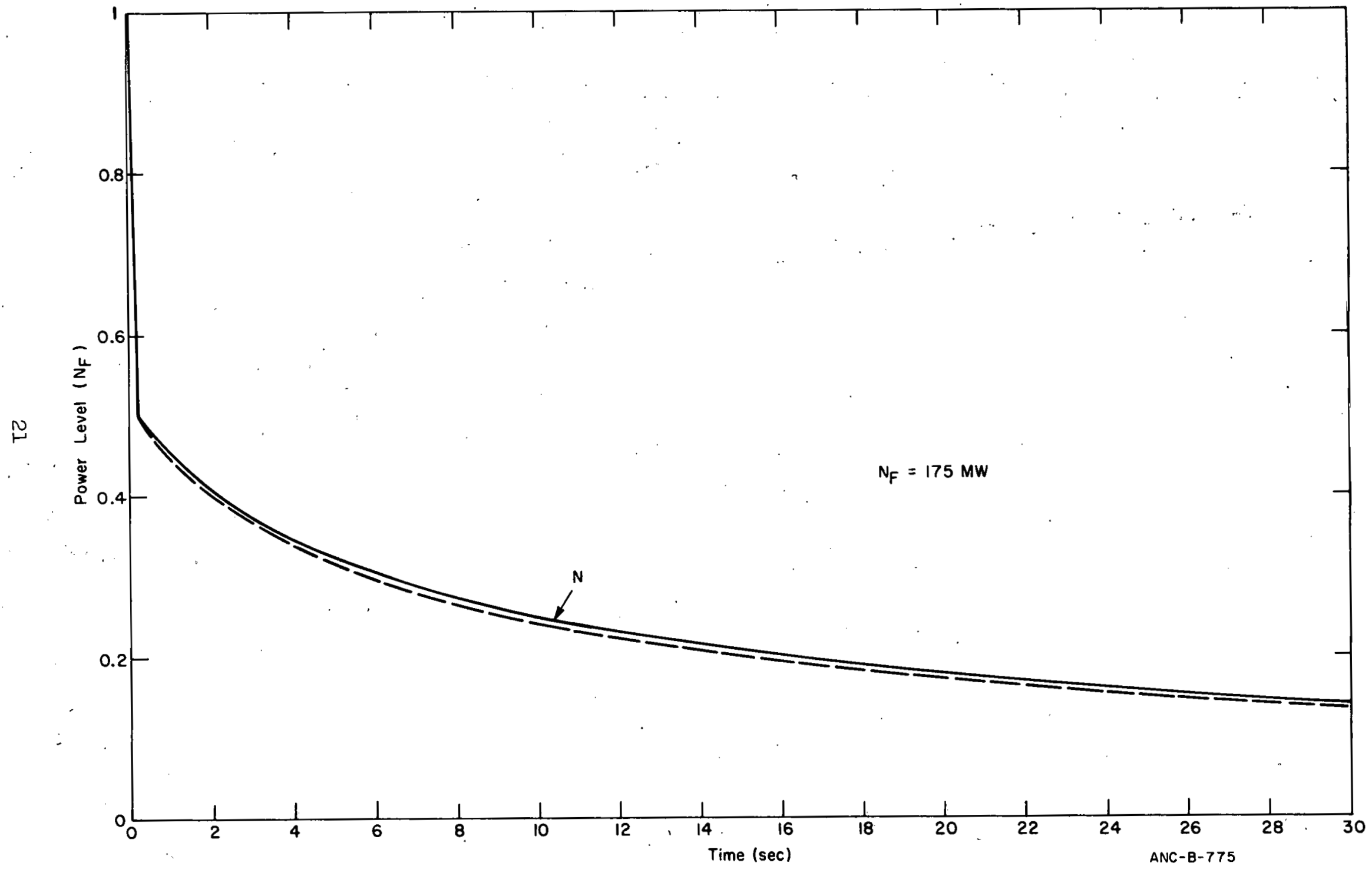

Fig. 14 . Effect of zero fuel temperature coefficient. 


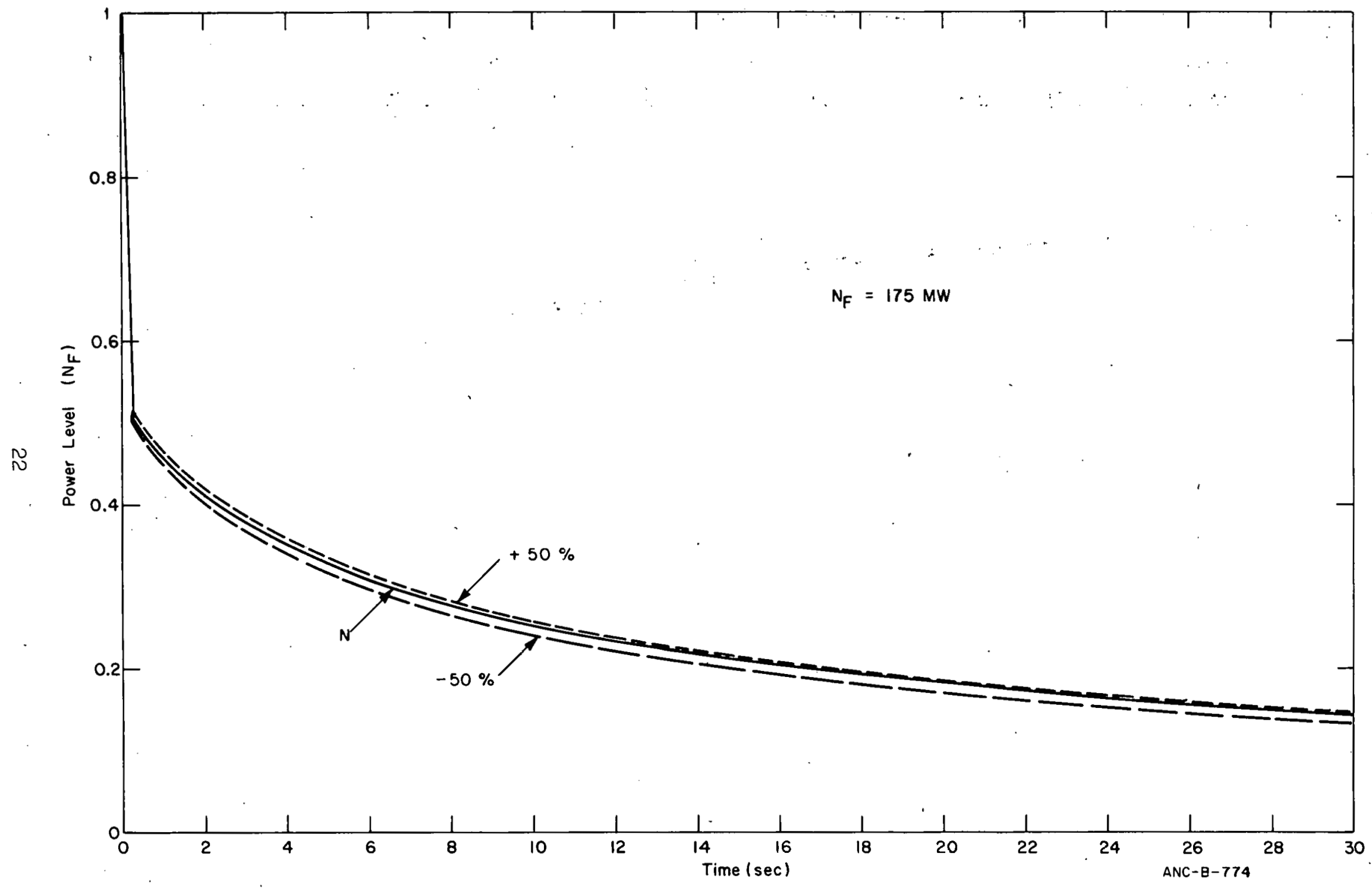

Fig. 15. Effect oi water temperature coefficient. 


\section{S'I'ABLLL'IY ANALYSLS'}

The feedback models described above were used for evaluating the stability of the reactor. In this analysis the zero-power reactor transfer function was combined with the feedback transfer functions to obtain the open-loop and closed-loop reactor transfer functions. The stability analysis was performed by application of Nyquist's stability criterion.

For the nominal feedback models (Case 1 of Table 1 and Figure 16) the stability analysis predicts an infirile gain margin and a phase margin of 110 degrees. The gain margin is defined as the net increase in system gain (product of reactor power level and feedback gain) required for the system to sustain small undamped oscillations about a steady state operating condition. Any further increase in system gain would result in divergent oscillations and the reactor would be unstable. The concept of an infinite gain margin as obtained in this analysis has meaning only for operating conditions for which the models used in the analysis are meaningful. For example, under steady power operation at less than full power with full flow and pressure and normal inlet coolant temperature, the models should be valid and they could be used for predicting stability. Under steady power operation above full power, full flow, etc., the models would be valid for stability analysis up to the point where the models would be expected to change such as at the onset of boiling in the core or experiments, fuel deformation, or melting, etc. At power levels where those conditions would occur the predicted infinite gain margin may not apply and, in fact, no definite statement concerning reactor stability can be made without using a new system model for those conditions. Very large or infinite gain margins are best used as

TABLE I

RELATIVE VALUES OF FEEDBACK MODEL PARAMETERS

\begin{tabular}{|c|c|c|c|c|c|}
\hline & Case 1 & Case 2 & Case 3 & Case 4 & Case 5 \\
\hline Prompt-negative feedback gain & Nominal & $\begin{array}{c}1 / 2 \mathrm{X} \\
\text { Nominal }\end{array}$ & 0 & Nominal & Nominal \\
\hline $\begin{array}{l}\text { Delayed-positive feedback } \\
\text { gain }\end{array}$ & Nominal & Nominal & Nominal & $\stackrel{2 \mathrm{X}}{\text { Nominal }}$ & $\begin{array}{c}2 \mathrm{X} \\
\text { Nominal }\end{array}$ \\
\hline $\begin{array}{l}\text { Delayed-negative feedback } \\
\text { gain }\end{array}$ & Nominal & Nominal & Nominal & Nominal & Nominal \\
\hline $\begin{array}{l}\text { Corresponding values of gain } \\
\text { margin }\end{array}$ & $\infty$ & $8: 0$ & 3.2 & 2.5 & 2.2 \\
\hline
\end{tabular}




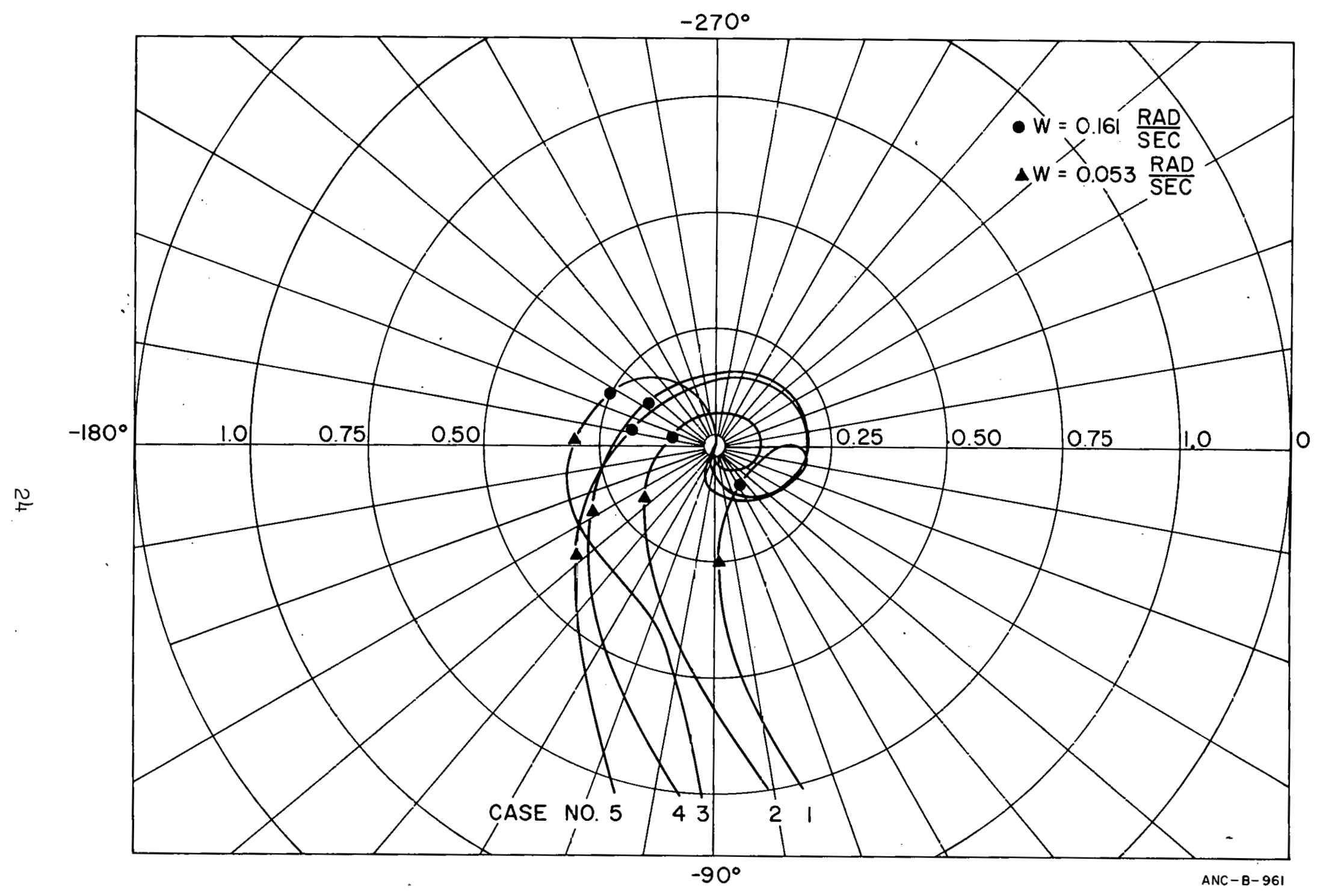

Fig. 16 Open-loop frequency response curves (Nyquist diagrams). 
indicators of relative stability over some range of operating conditions where the models are valid. In the case of the ETR the statement can be made that the reactor is extremely stable at conditions of full power (also at less than full power), full flow, normal inlet coolant temperature, etc. The infinite gain margin is a good indicator that the reactor is incapable of sustaining undamped oscillations at full power. The statement can also be made that the reactor is stable and well damped up to the point in operating conditions where the models fail to describe the operating conditions as in the case of boiling.

The stability of the reactor was also evaluated for various other values of the feedback model parameters. In Case 2 of Table I and Figure 16 , reducing the prompt-negative feedback gain $50 \%$ (water and fuel temperature coefficients of reactivity) results in a system with a gain margin of about 8 . Further reducing this gain to zero (Case 3 of Table I and Figure 16) results in a gain margin of about 3.2. This latter result, although not physically meaningful, still indicates an adequate margin of stability at full power. Sustained undamped oscillations would be predicted at about three times full power if no boiling occurs.

Two other cases of interest (Cases 4 and 5 of Table I and Figure 16) and perhaps more meaningful physically were analyzed resulting in smaller gain margins. In Case 4, the delayed-positive feedback gain was doubled. The corresponding gain margin was 2.5. This case indicates that undamped oscillation would occur at 2.5 times full power or at $f u l l$ power with another factor of 2.5 increase in delayed-positive feedback gain. The predicted frequency of oscillation in either event would be about $0.02 \mathrm{~Hz}$. The predicted five-fold gain increase over the nominal for the delayed positive feedback model is not believed to be possible because with such a large gain, agreement between the experimental and simulated rod drop power reduction curves would not have been obtained.

In Case 5 of Table I and Figure 16 the overall delayed feedback gain including both positive and negative components was doubled resulting in a gain margin of 2.2. This indicates undamped oscillations of $0.025 \mathrm{~Hz}$ at 2.2 times full power or at full power with this gain increased another factor of 2.2. This large a gain would also not have produced agreement with the experimental rod drop curve.

The smallest phase margin obtained from the stability studies was about 85 degrees. These large phase margins support the conclusions drawn from the gain margin information. 


\section{SUMMARY AND RECOMMENDATIONS}

The rod drop power transient has been analyzed and feedback models, both prompt and delayed, have been identified that produce good agreement between simulated power transients and the experimental power transient. The stability analysis using these models has shown that the reactor has an extremely high (theoretically infinite) margin of stability. From this analysis the possibility can be ruled out that the periodic power variations observed in the reactor at full power could have been the result of reactor instability or reactor oscillation.

The prompt drop regiun of the power curve shows an effective reactivity insertion time considerably smaller than is usually assumed in accident. calculations. Since this effect has safety implications it is recommended that some further investigations be performcd to resolve the discrepancy.

The prompt-negative feedback model used in the simulation required the addition of a fuel temperature reactivity coefficient in order to speed up the feedback. This effect also has safety implications and if it is as strong as indicated in this analysis it would have a strong mitigating effect on postulated reactivity accidents. Time and funding permitting an effort will be made to calculate a value for this coefficient using up-to-date data for the reactor core.

At this time the delayed-positive and negative fcedback models developed in this analysis do not appear to be greatly affecting reactor response or reactor stability. If the delayed positive component is indeed due to the experiment and experiment control responses as postulated in this report, it would be of interest for future such analyses to confirm the delayed-feedback models. It appears feasible, because of the low frequencies (large time constants) involved, to perform "oscillator" tests with the regulating rod about full power conditions that would yield information to confirm the models. If an experimental and analysis technique that does not require a large amount of reactor time or greatly perturbs the reactor is developed for this purpose, it could be used as a routine diagnostic test of reactor stability as experiments are added, removed, or modified. 


\section{APPENDTX .}

In this appendix more details are given concerning the feedback models.

The prompt-negative feedback equations used to develop the promptnegative feedback model are:

$\mathrm{M}_{f} \mathrm{C}_{f} \Delta \dot{\mathrm{T}}_{f}=\gamma_{f} \mathrm{K \Delta N}-\mathrm{UA}\left(\Delta \mathrm{T}_{f}-\Delta \mathrm{T}\right)[\mathrm{a}]$

$M C \Delta \dot{T}=\gamma_{W} K \Delta N+U A\left(\Delta T_{f}-\Delta T\right)-2 W C \Delta T$

where

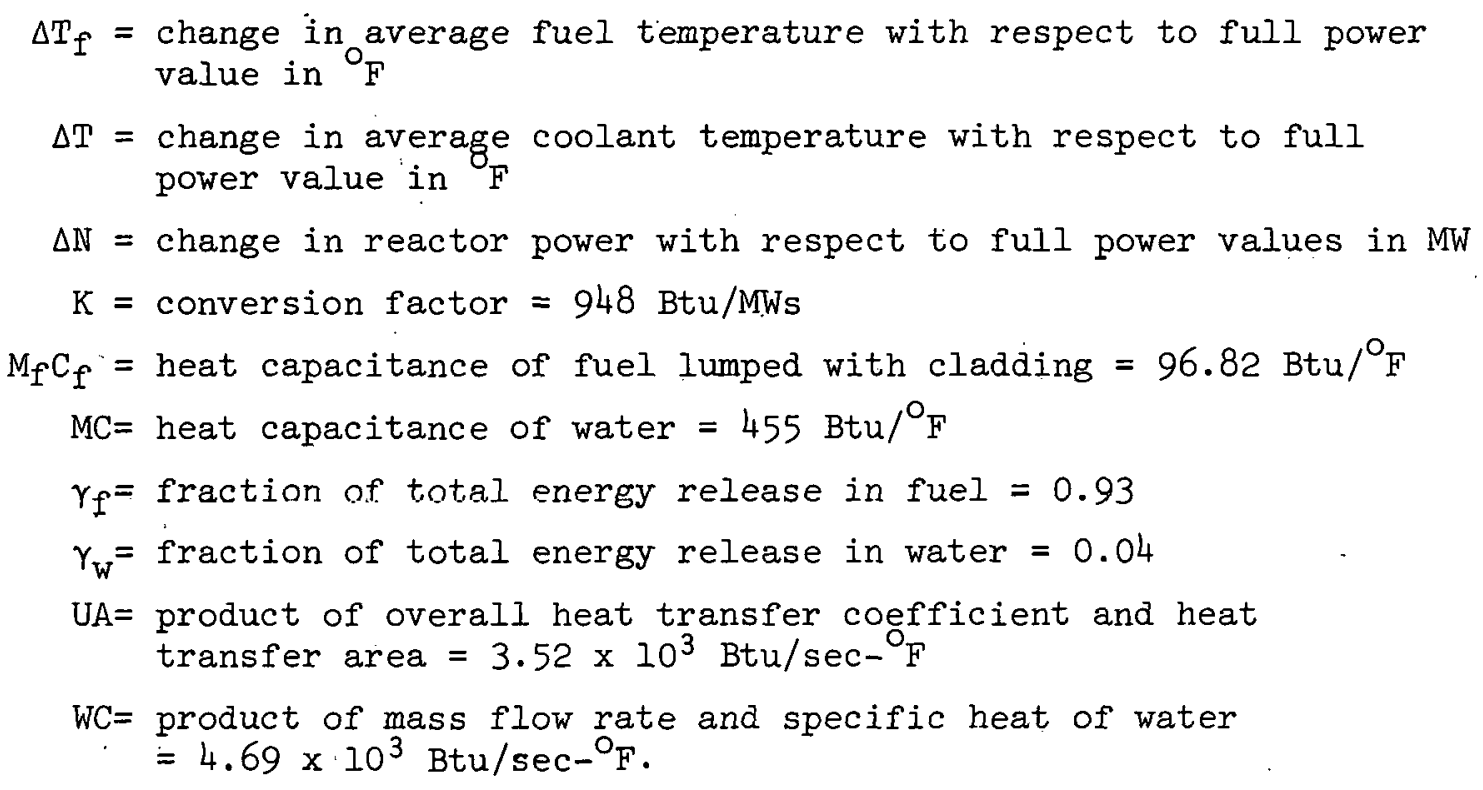

The prompt-negative feedback reactivity is related to the temperature changes according to Equation (7)

$\rho_{\mathrm{P}}^{-}=-\mathrm{C}_{\mathrm{T}_{\mathrm{W}}} \Delta \mathrm{T}-\mathrm{C}_{\mathrm{T}_{\mathrm{f}}} \Delta \mathrm{T}_{\mathrm{f}}$

where

$$
\begin{aligned}
C_{T_{W}} & =A+B \Delta T=\text { water temperature coeffirient in } \$ /{ }^{\circ} \mathrm{F} \\
C_{T_{f}} & =\text { fuel temperature coefficient in } \$ /{ }^{\circ} \mathrm{F} \\
A & =5.72 \times 10^{-3} \$ /{ }^{\circ} \mathrm{F} \\
B & =6.65 \times 10^{-5} \$ /\left({ }^{\circ} \mathrm{F}\right)^{2} .
\end{aligned}
$$

Taking Laplace transforms and combining Equations (5), (6), and (7) results in the transfer function:

[a] The dot represents differentiation with respect to time. 
$\frac{\rho_{P}^{-}(S)}{\Delta N(S)}=-\frac{C_{P}^{-}\left(\tau_{0} S+1\right)}{\left(\tau_{1} S+1\right)\left(\tau_{2} S+1\right)}$

The lumped system constants are related to the system physical parameters a.cording to:

$$
\begin{aligned}
& \tau_{1} \tau_{2}=\tau_{f} \frac{\tau_{w}}{2} \\
& \tau_{1}+\tau_{2}=\tau_{f^{\prime}}\left(1 .+\frac{U A}{2 W C}\right)+\frac{\tau_{w}}{2} \\
& \mathrm{C}_{\mathrm{P}}^{-}=\frac{1}{2} \frac{\delta \mathrm{T}_{\mathrm{CO}}}{\mathrm{N}_{\mathrm{O}}} \mathrm{C}_{\mathrm{T}_{\mathrm{W}}}\left[1+\frac{\mathrm{C}_{\mathrm{T}_{\mathrm{f}}}}{\mathrm{C}_{\mathrm{T}_{\mathrm{W}}}}\left(1+\frac{\gamma_{\mathrm{f}}}{\dot{\gamma}_{f}+\gamma_{\mathrm{W}}} \frac{2 \mathrm{WC}}{\mathrm{UA}}\right)\right] \\
& \tau_{0}=\frac{\frac{\gamma_{W}}{\gamma_{f}+\gamma_{W}} \frac{2 W C}{U A}\left[\frac{\gamma_{f} C_{T_{f}}}{\gamma_{W} C_{T_{W}}}+\frac{M_{f} C_{f}}{M C}\right] \frac{\tau_{W}}{2} .}{1+\frac{C_{T_{f}}}{C_{T_{W}}}\left(1+\frac{\gamma_{f}}{\gamma_{f}+\gamma_{W}} \frac{2 W C}{U A}\right)}
\end{aligned}
$$

and

$$
\begin{aligned}
& \tau_{f}=M_{f} C_{f} / U A \\
& \tau_{W}=M C / W C=\text { transport time of water through corc region } \\
& \delta \mathrm{T}_{\mathrm{C}_{0}}=\begin{array}{l}
\text { temperature rise of water across core region at full } \\
\text { power }=50 \mathrm{~F}[2] .
\end{array} \\
& \mathrm{N}_{O}=\mathrm{N}_{F}=175 \mathrm{MW} .
\end{aligned}
$$

The static prompt-negative power coefficient, $\mathrm{C}_{\mathrm{p}}^{-}$, evaluated at full power has the value $0.114 / \mathrm{MW}$. The experimental values of the power coefficient reported in Ref. [6], pages 163-164, range between 0.196 and $0.302 \phi / \mathrm{MW}$ depending on reactor operating conditions. Values of the power coefficient this large would produce an undershoot problem in the simulated response and so could not be used in the simulation. On the basis of these simulation studies it would appear that using the extrapolated water temperature coefficient from Ref. [5] and a fuel temperature coefficient produces better agreement in this experiment than the power coefficient data of Ref. [5]. 
The delayed-feedback transfer function obtained from the simulation studies has the form

$\frac{\rho_{D}(S)}{\Delta N(S)}=-C_{D} \frac{1-\tau_{5} S}{\left(\tau_{3} S+I\right)^{2}}$

where

$$
C_{D}=\frac{K_{D}^{+}}{\tau_{5}}=4.56 \times 10^{-4} \$ / \mathrm{MW}=0.0456 \phi / \mathrm{MW}
$$

Expressed in this form it is seen that the delayed feedoack has a negative static power coefficient about 4/10 as large as the static prompt power coefficient. The delayed-positive feedback is seen to be strictly a rate effect.

The overall feedback transfer function is defined as

$$
H(S)=\frac{\rho_{P}^{-}(s)+\rho_{D}(s)}{\Delta N(S)}=\frac{-C_{P}^{-}\left(\tau_{0} S+1\right)}{\left(\tau_{1} S+1\right)\left(\tau_{2} S+1\right)}-\frac{C_{D}\left(1-\tau_{5} S\right)}{\left(\tau_{3} S+1\right)^{2}} .
$$

From the zero-power kinetics equations, the zero-power transfer function $G_{0}(S)$ can be derived:

$$
G_{0}(S)=\frac{\Delta N(S)}{\rho(S)}=\frac{N_{0}}{S\left[\frac{\ell}{\beta}+\sum_{i=1}^{6} \frac{a i}{S+\lambda i}\right]}
$$

where

$$
\begin{aligned}
\rho(S) & =\text { net reactivity in } \$ \\
N_{0} & =\text { steady state power in } M W \\
\beta / \ell & =160 \mathrm{sec}^{-1}, \text { prompt neutron decay constant } \\
a_{i}, \lambda_{i} & =\text { delayed neutron constants. }
\end{aligned}
$$

The, closed-loop transfer function, assuming rod reactivity as the input and the change in power as the output is

$\frac{\Delta \mathrm{N}(\mathrm{S})}{\rho_{\mathrm{Rod}}(\mathrm{S})}=\frac{\mathrm{G}_{\mathrm{O}}}{1-\mathrm{G}_{\mathrm{O}} \mathrm{H}}$

The stability of the reactor is determined by analysis of the roots of the characteristic equation

$1-G_{0} H=0$ or $G_{0} H=1$. 
If the roots of the characteristic equation all have negative real parts the system is stable at the operating condition. In this analysis, rather than factoring Equation (13) to determine the roots, the Nyquist stability criterion was used because it was a more convenient test for stability to implement than olhers such as the root locus or Routh's test. 


\section{REFERENCES}

[1] N. C. Kaufman, Aerojet Nuclear Company, private communication, Feb. 8, 1972.

[2] A. D. Mackley, Aerojet Nuclear Company, private communication, Feb. 15, 1972.

[3] C.. F. Obenchain, A Program for the Analysis of Reactor Transients (PARET), IDO-17282, Jan. 1969.

[4] Engineering Test Reactor (ETR). Engineering Design and Safeguards Report, IDO-24020, July 1956.

[5] D. W. Knight, "ETR Bulk Water Temperature Coefficient", Nuclear Technology Division Annual Progress Report for Period Ending June 30, 1971, ANCR-1016 (Oct. 1971).

[6] A. D. Mackley, "ETR Power Coefficient Measurements", Nuclear Technology Division Annual Progress Report for Period Ending June 30, 1971, ANCR-1016 (October 1971), pp 163-164. 


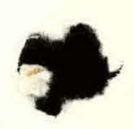

